DOI: https://doi.org/10.3126/njdrs.v17i0.34947

\title{
Peer Review Process in Scholarly Communication and Scientific Publishing
}

\author{
Bishnu Bahadur Khatri \\ Associate Professor at Central Department of Rural Development \\ Tribhuvan University, Nepal \\ Email for corresponding: khatri.bishnu@gmail.com/khatri.bishnu@cdrd.edu.np
}

\begin{abstract}
Peer review in scholarly communication and scientific publishing, in one form or another, has always been regarded as crucial to the reputation and reliability of scientific research. In the growing interest of scholarly research and publication, this paper tries to discuss about peer review process and its different types to communicate the early career researchers and academics. This paper has used the published and unpublished documents for information collection. It reveals that peer review places the reviewer, with the author, at the heart of scientific publishing. It is the system used to assess the quality of scientific research before it is published. Therefore, it concludes that peer review is used to advancing and testing scientific knowledgeas a quality control mechanism forscientists, publishers and the public.
\end{abstract}

Key words: Peer review, scholarly communication, scientific publication

\section{Introduction}

Scholarly communication and scientificpublication is challenging but essential task in academic world. It takes resources, time and interest to complete high-quality research (Schwebel \& Morrongiello, 2017). Moreover, publication in the journals following standard publication practices is considered one of the most effective means for scholarly communication in scientific publication (Daniel, 2005; Loue, 2007). Scholarly communication is the process of sharing, disseminating and publishing the research findings of academics and researchers so that the generated academic results are made widely available and communicated to the global academic communities (Das, 2015). It forms a life-cycle of steps involved in the creation, publication, dissemination and discovery of scholarly research. However, scientific publishing enables research outcomes to be disseminated to the academic community and the public, primarily through journal articles and monographs, as well as conference proceedings, working papers, and datasets.

In this connection, peer review or "certification" is a central to ensure the validity and integrity of the scientific publication process; itplaces the reviewer, with the author, at the heart of scientific publishing. It is the system used to assess the quality of scientific research before it is published. In fact, the reviewer scrutinises for its validity, originality and significance, at the same time it detects the plagiarism and fraud (Sense about Science, 2012). Historically, it is thought that "The Philosophical Transactions of the Royal Society"was a first journal to formalize the concept of peer review under Nepalese Journal of Development and Rural Studies, Volume 17 
the editorship of Henry Oldenburg (1618-1677) and began systematically publishing research results in 1665 . It has continuedsuccessfully with relatively minor changes for some 350 years (https://www. elsevier.com/reviewers). Scientific publishing has been evolving rapidly since the 2000s and most radically in the last few years with open science policies particularly due to reproducibility requirements.

Peer review is critical because it plays a central role in academic career development. For this purpose, peer review process is widely used in scholarly communication and scientific publication. It upholds a quality control mechanism and widely accepted method for research validation. This paper tries to familiarize the early career researchers about how peer review process works in scholarly publication in an academic world and discuss on its different flavors.

\section{How the Peer Review Process Works}

Peer reviewing is particularly important for earlycareer researchers because it allows them to gaininsights into other developments in their researcharea and plays a greater role in their researchcommunity (Sense about Science, 2012). There are three key roles in peer review: the authors who write the papers, the reviewers who provide expertopinions and advice, and the editors who make the decisions. The peer review processare presented below (Figure $1 \&$ Figure 2):

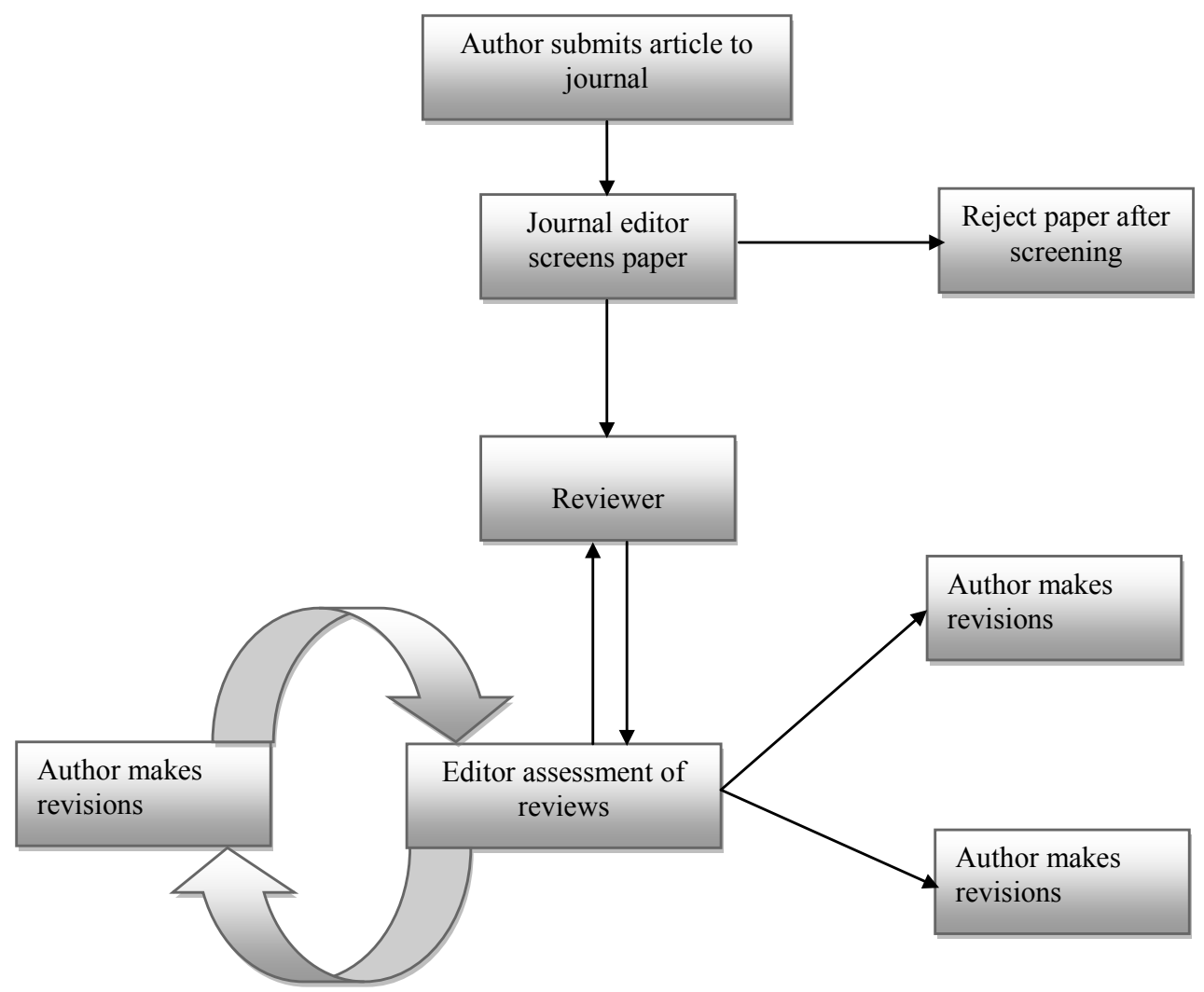

Figure 1. Diagram of "Typical” Peer Review process

(Sense about Science, 2012) 


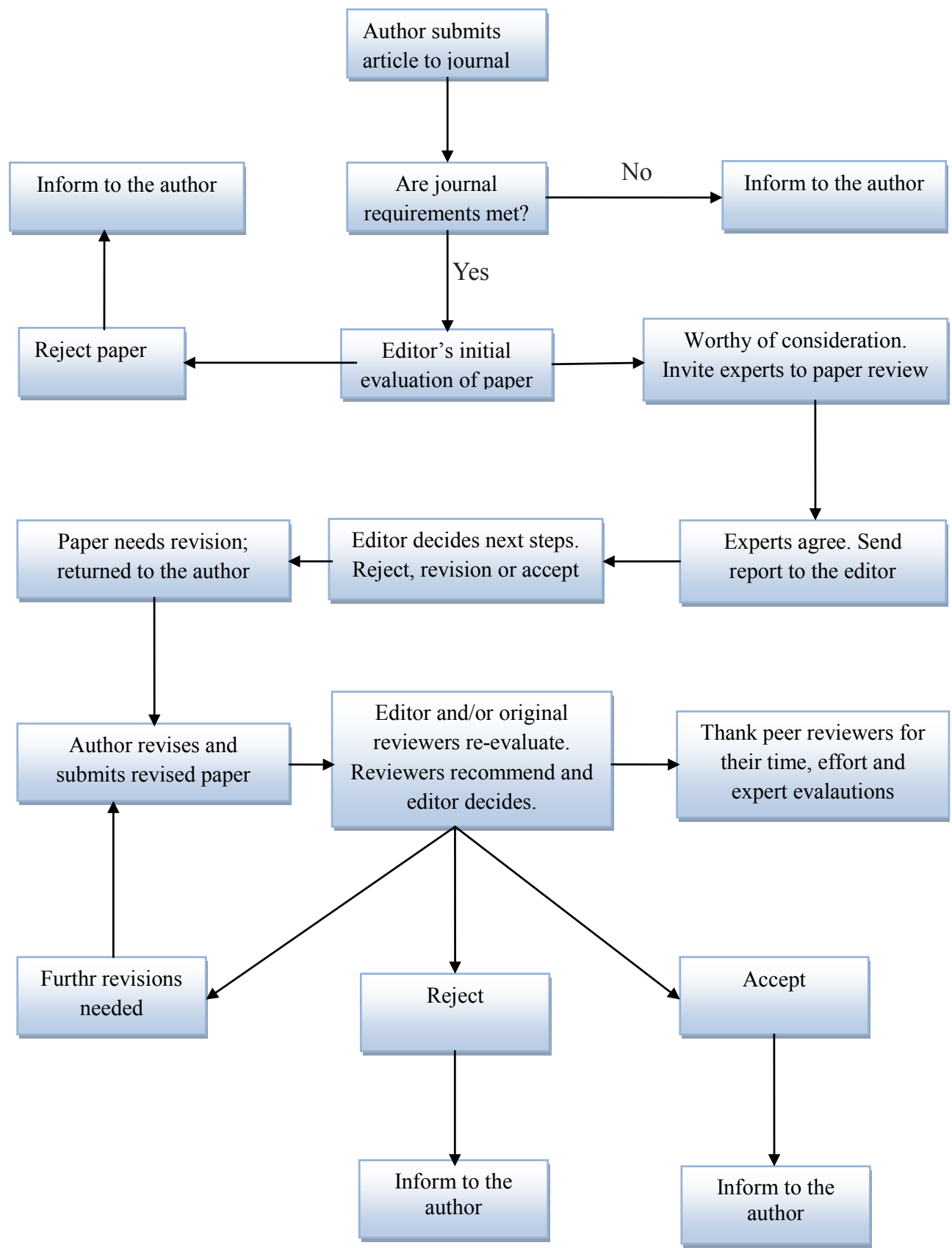

(www.elsevier.com, 2021)

\section{Figure 2. Diagram of Peer Review Process}

Nepalese Journal of Development and Rural Studies, Volume 17 


\section{Different Flavors/Types}

Peer review comes in different flavors, you must therefore check which variant is employed by the journal on which you are working so you're aware of the respective rules. In this regards, peer review varies considerably between scientific disciplines; it is not a one-size-fits allprocess (The House of Commons, 2011). Basically, four different types of peer review processes (i.e "single-blind review", "double-blind review" triple-blind review" and "open review") practicing in academic publication are briefly highlighted below:

Single-blind review. This is a traditional method of reviewing. In this type of review, the reviewers know who the authors are, but the authors do not know whothe reviewersare. The most common system in science disciplines. The single blind review considers the following points: a) Reviewer anonymity allows for impartial decisions - the reviewers should not be influenced by the authors, b) authors may be concerned that reviewers in their field could delay publication, giving the reviewers a chance to publish first, and c) reviewers may use their anonymity as justification for being unnecessarily critical or harsh when commenting on the authors' work.

Double-blind review. In this review model, both the reviewer and the author are anonymous. For journals that use double-blind peer review, the identities of both reviewers and authors are concealedfrom each other throughout the review. To facilitate this, authors must ensure that their manuscripts areprepared in such a way that they do not reveal their identities to reviewers, either directly or indirectly (https://www.elsevier.com/reviewers/). The reviewers do not know who the authors are, and the authors do not knowwho thereviewers are. Main form of peer review used in the humanities and social sciences. The double blind review has more advantages than others, are listed as: a) Author anonymity limits reviewer bias, for example based on an author's gender, country of origin, academic status or previous publication history, and b) articles written by prestigious or renowned authors are considered on the basis of the content of their papers, rather than their reputation.

Triple-blind review. In this triple-blind review, reviewers are anonymous and the author's identity is unknown to both the reviewers and the editor. Articles are anonymized at the submission stage and are handled in such a way to minimize any potential bias towards the author(s). However, it should be noted that: a) the complexities involved with anonymizing articles/authors to this level are considerable, b) as with double-blind review; there is still a possibility for the editor and/or reviewers to correctly divine the author's identity from their style, subject matter, citation patterns or a number of other methodologies.

Open review. The most common definition of open review is when both the reviewer and author are known to each other during the peer review process. It can also mean inclusion of the reviewers' names and/or reportsalongside the published paper, comments from others (subject community or widerpublic) at pre-publication stage, or various combinations of these (Sense about Science, 2012). In general transparencyis the key to trust in peer review. Open review has greater transparency during and after the peer review process.

\section{Conclusion}

Knowledge advances through scholarly research, research communication and scientific publishing. Peer review places the reviewer, with the author, at the heart of scientific publishing. Reviewers make the editorial process work by examining and commenting on manuscripts. Without 
peer review there is no control in scientific communication. Therefore, reviewers are the backbone of the whole process and peer review is a certification model that ensures the validity, integrityand trustworthinessof the scholarly communication and scientific publication.

\section{References}

Daniel, H. D. (2005). Publications as a measure of scientific advancement and of scientists' productivity. Learned Publishing, 18(2), 143-148. doi:10.1087/0953151053584939.

Das, A. K. ( 2015). Introduction to scholarly communication', in UNESCO curriculum for researchers, module 1: Scholarly communications. In M. P. Satija \& S. Mishra (Eds.) UNESCO, Paris, 2015, 5-16. Retrieved from http://eprints.rclis.org/24814/.

https://www.elsevier.com/reviewers/. Accessed on 03 January, 2021

Loue, S. (2007). Textbook of research ethics: Theory and practice. Springer Science \& Business Media.

Schwebel, D. C. \& Morrongiello, B. A. (2017). Musings on developing research ideas. BehavTher (N Y N Y), 39(6), 211-212.

Sense about Science (2012). Peer review: the nuts and bolts. A guide to peer review written by early career researchers for early career researchersRetrieved from https://senseaboutscience.org/ activities/peer-review-the-nuts-and-bolts/. Accessed 03 January, 2021.

The House of Commons (2011). Peer review in scientific publications. London: The Stationery Office Limited. 